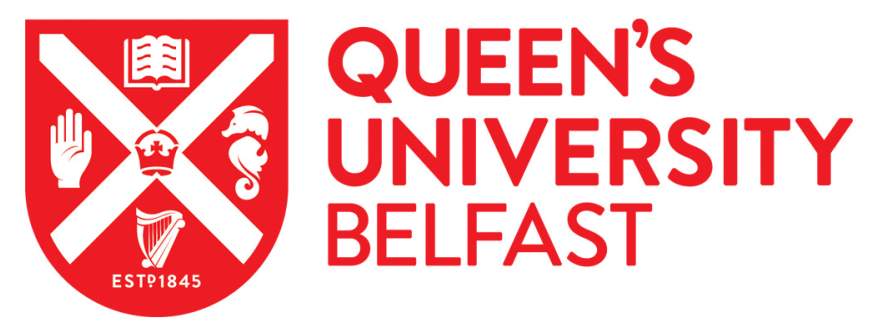

\title{
Patient's perspectives of living with a precancerous condition: monoclonal gammopathy of undetermined significance (MGUS)
}

\author{
Murphy, B., McShane, C., Santin, O., Treanor, C., Bryne, B., Donnelly, M., \& Anderson, L. (2021). Patient's \\ perspectives of living with a precancerous condition: monoclonal gammopathy of undetermined significance \\ (MGUS). European Journal of Oncology Nursing, 51, [101901]. https://doi.org/10.1016/j.ejon.2021.101901
}

Published in:

European Journal of Oncology Nursing

Document Version:

Peer reviewed version

Queen's University Belfast - Research Portal:

Link to publication record in Queen's University Belfast Research Portal

\section{Publisher rights}

Copyright 2021 Elsevier.

This manuscript is distributed under a Creative Commons Attribution-NonCommercial-NoDerivs License

(https://creativecommons.org/licenses/by-nc-nd/4.0/), which permits distribution and reproduction for non-commercial purposes, provided the author and source are cited.

\section{General rights}

Copyright for the publications made accessible via the Queen's University Belfast Research Portal is retained by the author(s) and / or other copyright owners and it is a condition of accessing these publications that users recognise and abide by the legal requirements associated with these rights.

Take down policy

The Research Portal is Queen's institutional repository that provides access to Queen's research output. Every effort has been made to ensure that content in the Research Portal does not infringe any person's rights, or applicable UK laws. If you discover content in the Research Portal that you believe breaches copyright or violates any law, please contact openaccess@qub.ac.uk. 
34 Abstract:

1 Figure

Authors: Blain Murphy1, Charlene M. McShane2, Olinda Santin3, Charlene Treanor2, Bronagh Bryne2, Michael Donnelly2, Lesley A. Anderson2,4

1. Institute for Global Food Security (IGFS), School of Biological Sciences, Queen's University Belfast, UK

2. Centre for Public Health, Queen's University Belfast, UK

3. School of Nursing and Midwifery, Queen's University Belfast, UK

4. Aberdeen Centre for Health Data Science, University of Aberdeen, UK

Corresponding author: Prof. Lesley A. Anderson, Aberdeen Centre for Health Data Science, University of Aberdeen, UK lesley.anderson@abdn.ac.uk gammopathy of undetermined significance (MGUS) 
1 Purpose:

2 The aim of this study was to investigate patient experiences of living with

3 monoclonal gammopathy of undermined significance (MGUS). Living with a

4 premalignant condition such as MGUS may elicit negative psychosocial effects

5 including increased anxiety and fear of progression to cancer. To date, no study

6 utilising qualitative methodology has explored the lived experiences of MGUS

7 patients.

8 Methods:

9 Data was collected via two focus groups and six telephone interviews. MGUS patients

$10(n=14)$ were recruited via nurse-led hematology telephone-clinics in Northern

11 Ireland. Interviews were transcribed verbatim and the data subjected to thematic

12 analysis.

\section{Outcome:}

Thematic analysis identified 3 overarching themes; (1) The psychosocial impact of an MGUS diagnosis, (2) Knowledge of MGUS and (3) Experiences of MGUS health services. Patients with MGUS reported experiencing poor psychological adjustment to their condition particularly at the point of diagnosis and approaching follow-up appointments. Feelings of isolation, poor information-provision, increased uncertainty and limited psychosocial support for MGUS patients were also reported. Patients did however reflect positively on their experience of being followed up via nurse-led telephone clinics.

\section{Conclusions:}

Provision of patient friendly information guides at diagnosis, and additional psychosocial support services such as nurse-led telephone clinics and coordinated patient groups may help MGUS patients adjust better to their diagnosis and in doing so improve quality of life in this patient population.

\section{Key words:}

32 Monoclonal gammopathy of undetermined significance (MGUS), multiple myeloma, Quality of life, Qualitative, Precancer. 
1 Monoclonal gammopathy of undetermined significance (MGUS) is an asymptomatic premalignant blood disorder which precedes multiple myeloma (MM), an incurable B-cell malignancy (Kyle et al., 2006). The annual rate of progression to MM and related lymphoproliferative disorders such as Waldenström's macroglobulinemia, and lymphoma has been reported to be $1 \%$ (Kyle et al., 2002), meaning the vast majority of individuals diagnosed with MGUS will not progress to MM. MGUS is more common in males (Wadhera and Rajkumar, 2010), and individuals of black ethnicity (Landgren et al., 2007, 2006). Younger age at diagnosis has been reported among black individuals (median age of diagnosis: 66 vs 70 years old (white individuals ) (Landgren et al., 2017). MGUS prevalence is estimated to be $3.2 \%$ in adults over 50 years old, however, most individuals remain undiagnosed due to the asymptomatic nature of presentation (Kyle et al., 2006; Therneau et al., 2012).

MGUS patients often experience considerable hospital activity pre- and postdiagnosis, implying diagnosed cases are living with comorbidities (Lamb et al., 2019). MGUS is typically detected incidentally during investigations for other conditions, with an elevated total protein level leads to serum protein electrophoresis (SPE) which detects a paraprotein (International Myeloma Working Group, 2003; Kyle et al., 2010). Individuals are diagnosed when a reduction of one or more immunoglobulin class ( $\lg G, \lg A$ and $\lg M$ ) levels are detected from a serum protein electrophoresis (SERP) test (Bird et al., 2009). The International Myeloma Working Group (IMWG) defines the parameters of MGUS as having a serum M protein $<30 \mathrm{~g} / \mathrm{l},<10 \%$ clonal plasma cells (PCs) in the bone marrow and, most importantly, the absence of endorgan damage that can be attributed to the $\mathrm{PC}$ proliferative disorder or other B-cell proliferative disorders (International Myeloma Working Group, 2003; Kyle et al., 2010). Once diagnosed, it is recommended that MGUS patients are followed-up regularly (every 3-12 months) to identify early signs of progression to MM (Bird et al., 2009; Smith et al., 2007). Within the UK, this is often conducted by clinical nurse specialists (CNS) utilising telephone clinics for low-risk patients; under the guidance of haematology consultants (Rawstron et al., 2007).

Studies investigating the quality of life of patients with haematological precancerous conditions is limited. Recent quantitative cross-sectional research on MGUS and smouldering multiple myeloma (another higher risk MM precursor) has indicated that these patients exhibit similar psychological distress and mental health-related quality of life (HRQoL) as patients with active MM (cancer) (Maatouk et al., 2019). Compared to MM, MGUS is considered to be asymptomatic with the literature suggesting minimal physical impact (Kyle et al., 2011). Similar qualitative studies of other precancerous conditions, such as Barrett's oesophagus, identified a lack of social support, poor information provision and negative psychological reactions, e.g. 
1 increased anxiety, as central concepts of living with a diagnosis of a premalignant 2 condition (Kennedy et al., 2012; Lee Mortensen and Adeler, 2010). This study aimed

3 to illustrate the experiences of receiving and living with a MGUS diagnosis.

4

\section{Design}

7

8

9

\section{Methods}

This study was a qualitative design, which utilised an integration of focus groups and telephone interviews to collect and integrate the data. The Consolidated Criteria for Reporting Qualitative Studies (COREQ) (Tong, Sainsbury, \& Craig, 2007) guided the reporting of the study. Participants were identified using convenience sampling and recruited during their routine telephone surveillance appointment by CNS' at two Healthcare trusts (Belfast and Southern) in Northern Ireland. During these appointments the CNS discusses patient's blood test results and assesses their general health; with a goal of identifying potential signs of progression such as increased infections, bone pain and/or fractures (Rawstron et al., 2007). All patients on telephone follow-up were considered low risk for progression.

Prior to invitation, the CNS assessed each patient against eligibility criteria. Individuals were not eligible if they were considered to be too frail or had neurocognitive difficulties or severe mental health issues which could affect their ability to provide consent. The CNS introduced the study to participants during their routine telephone appointment. Interested patients were mailed a study information pack (containing a study information booklet, a consent sheet, a contact information sheet, a pen and a prepaid envelope to return the consent and contact information forms) by the CNS. Suitable times for the focus group/interview were then organised by the university-based study team by telephone call. Non-responders received a reminder telephone call from the CNS after two weeks. No patient had a prior relationship with the research team; the latter was separate to the clinical team involved in recruitment. Prior to recruitment, study documentation was reviewed by a subset of (non-MGUS) patients in the Northern Ireland Clinical Trials Centre 'Personal and Public Involvement in Research' committee.

Both the interviews/focus groups followed a semi-structured schedule (Appendix 1) developed by the study team in consultation with the published literature. Data was collected via two focus groups and six telephone interviews with MGUS patients aged 40-70 years old in 2015-16. Poor focus group recruitment led to incorporating telephone interviews to increase numbers and provide a wider range of opinions and individuals (Stokes and Bergin, 2006). Patients were offered the choice with all preferring the interviews. This multi-method monostrand design (combining focus 
1 groups and interviews) a more holistic approach to the data richness (Barbour, 2014).

2 A critical review endorsed this integration of the methods as it "leads to an enhanced

3 description of the phenomenon's structure and its essential characteristics" (Stokes

4 and Bergin, 2006).

5

Focus groups were led by an experienced qualitative researcher (OS or CT; both female with expertise outside MGUS field) while two other study team members (CMCS and BB; both female with expertise in the area) attended to take notes and assist with logistics. Focus groups took place within a non-clinical setting and lasted approximately one and a half hours. Telephone interviews lasted approximately 30 minutes and were conducted by BM (male with MGUS research expertise). Focus groups and interviews were recorded on a digital voice recorder, transcribed verbatim, and rechecked against the recordings and relevant field notes. Recruitment was carried out until a point of saturation meaning that "sufficient data to account for all aspects of the phenomenon were obtained" (Morse et al., 2002). Draft transcripts (one-page extract) were sent to a subset of patients $(n=7)$ for respondent validation.

\section{Data analysis}

Transcripts were analysed using inductive thematic analysis (Braun and Clarke, 2006) following the 6-step trustworthiness criteria (Nowell et al. (2017). As such, interviews were conducted and data were gathered, coded and analysed by at least two researchers independently and then these data rounds were discussed by the two researchers and presented to members of the wider interdisciplinary research team for further analytical discussion. The iterative rounds continued until there was agreement that no new data or no new themes emerged from the transcripts. The data was organised using NVIVO v11 (QSR International Pty Ltd, 2015). Theme development was similar between the data collection methods. Verbatim quotations were used to provide evidence for the researchers' interpretations.

\section{Ethics considerations}

Ethical approval was obtained from the Office for Research Ethics Committee Northern Ireland (Ref: 13/NI/0073). Informed consent was obtained from all study participants. A distress protocol was in place due to the potential for participants to become distressed while recalling their lived experiences. At the end of the focus group/telephone interview, participants were provided with an information pack via post; containing an information leaflet and contact details for charitable agencies (example, Myeloma UK\Bloodwise) for additional information or support if interested. 


\section{Results}

2 In total, 14 individuals participated in this study: $n=8$ focus group participants (focus 3 group $1 \mathrm{n}=6$, focus group $2, \mathrm{n}=2$ ), and six participated in telephone interviews (TI 1-

4 6). The participants were predominantly male $(n=8 / 14)$, married $(n=13 / 14)$ and 5 educated to at least GCSE or O-level/high school standard $(n=14)$ (Table 1). All 6 patients were being followed-up for their MGUS diagnosis via nurse-led telephone 7 clinic at 3-12 month intervals. Patients varied on time since diagnosis (from $<1$ year 8 to $>8$ years). Six patients reported co-morbid long-term conditions (specific 9 information on these conditions were not captured).

10 Thematic analysis identified 3 overarching themes; (1), The psychosocial impact of an 11 MGUS diagnosis, (2) Knowledge of MGUS and (3) Experiences of MGUS health 12 services, Figure 1. 
1 The psychosocial impact of an MGUS diagnosis

2 The first major theme identified was the psychosocial challenges of an MGUS

3 diagnosis and how this fluctuated across the MGUS pathway. In particular, patients

4 discussed heightened emotions at diagnosis, including shock and fear. Interaction

5 with cancer services also invoked social comparisons with cancer patients and

6 increased fears of progression.

8 Patients described their diagnosis as "the shock of my life" (TI.2), with some viewing

9 their diagnosis as an existential threat to their future. Patients reported completing

10 wills and purchasing cemetery plots. These patients wanted more information and

11 appeared to have been more anxious at diagnosis than other participants. However,

12 all patients were aware of the potential for progression to cancer and reported some 13 initial anxiety relating to this.

"To realise that this had the potential to be cancerous was a shock and it certainly made me think about my mortality which I had-...obviously had thought about before but I thought about it even more and I did make a will and I did buy a grave (laughing). Basically I thought "Right I better start getting organized, just in case this leads to something awfully terrible". TI.2

For many patients, the shock developed into anxiety post-diagnosis; with patients describing consistent thoughts about their mortality during this time. The impact of the diagnosis and hearing the term 'cancer' led to some missing important MGUS information during the initial consultation. This shock and anxiety was present until their follow-up appointment, usually 3 months' post-diagnosis; when patients could ask questions and process the information better.

The psychosocial impact seemed to reduce over time; as patients came to terms with their condition. Most patients had lived with MGUS for many years and their worries about the consequences lessened over time. Their fear of progression to cancer was compared to "Damocles sword" FG2.2; a consistent but mainly dormant fear. Their fear that their next appointment could be the appointment they received bad news from the CNS and had progressed to cancer.

"I think it's sort of a Damocles, hanging very high-- you know, it sort of-- not likely-Sort of a high percentage chance of not developing anything". FG2.2

For some patients, MGUS was a spur to improve their lives and make lifestyle changes, with patients reporting increased physical activity and improving their diet 37 to lessen their risk of progression. 
"I'm trying to do a bit of running. So it maybe gave me a little bit a kick in the backside to go out and do something, lose a bit weight. It's-- it was good that way. Was it because of that? Yeah, but that was only maybe more in the mind to, you know, I've got to do something to look after. I thought I was going to die from a heart [condition] rather than of MGUS". FG2.2

MGUS was often overshadowed by medical issues of friends/family, especially if cancer-related. Patients felt that their MGUS diagnosis was less important and tried to avoid causing worry and anxiety by not talking about their MGUS diagnosis. As a result, some patients felt isolated with their diagnosis; having no-one to speak to about their worries. Male participants were particularly reluctant to speak about their MGUS diagnosis due to their lack of understanding about the condition and burden this may place on their families/friends. The asymptomatic nature led to some patients comparing it to a mental health diagnosis; where patients were healthy on the outside but unwell inside.

"Cause it's asymptomatic, so there are no symptoms associated with MGUS. It's seems to be that it's a hidden illness. So that may be one of the reasons why people don't really know much about it." FG2.2

\section{Patient's knowledge of MGUS}

The second major theme identified was how patient's knowledge of MGUS affected the MGUS experience; particularly around acquiring knowledge from HCPs and the Internet. While some patient-friendly information helped patients to be more confident about their diagnosis and take an active role in their own care, poor information led to decreased psychosocial wellbeing.

Patients found the full name (monoclonal gammopathy of undetermined significance) difficult to understand, remember and explain to others; such as family and friends. Confusion was heightened by the differing terminology used by HCPs when they were trying to explain the condition to patients. Patients reported that MGUS was described to them by HCPs as a; "protein deficiency" (FG1.4), "raised protein" (TI.4)", "benign blood abnormality" (TI.2) and a "rogue blood in my system" (TI.3). Many felt this was a contributing factor to their confusion and anxiety at diagnosis.

"What does the word (MGUS)-- what does the 4 letters mean?"FG1.2

"Monoclonal gammopathy of undermined significance." Interviewer: 
There were significant differences in patient's actual and desired level of knowledge. Some patients reported wanting to "live in a bubble" (FG1.3) and did not wish to know anything beyond the essential information; such as when their appointments were. On the other hand, other patients kept detailed records of their blood scores (e.g. free-kappa-lambda ratio). For these patients, feeling informed created a sense of empowerment through feeling that they were an active participant of their care. These patients were able to describe the link between MGUS and MM and lymphoma and define the progression risk to MM "1\% per annum" (TI.4). Other patients reported their knowledge as low to medium and many desired to improve their 11 knowledge.

Patients who did not receive information leaflets at diagnosis reported more extensive online knowledge seeking than those who did. Patients described their experiences of searching for MGUS information online as challenging and websites difficult to navigate; with most of the information using unfamiliar and complex language or referring to information in other countries (especially the USA). As a result, many patients were linked/directed to MM (not MGUS) information, which caused significant anxiety and worry particularly if identified shortly after diagnosis. Patients illustrated how they found negative and fear-inducing stories when searching online at diagnosis; as they lacked the understanding to differentiate MGUS and MM information.

\section{"I sort of looked up what MGUS was. I looked up online and I sort of had a fair idea} what it was well sort of an idea what it was so I was probably a wee bit apprehensive because I thought it's possible-... / could not have cancer but I could possibly be getting cancer so / did feel a bit (shocked) ". TI.2

Patients interacted with HCPs in order to gain information in relation to MGUS to educate and empower themselves. Patients sought information from three types of HCP; their haematology team (doctors and clinical nurse specialists), their GP and personal contacts within healthcare who were HCPs.

Patients described how receiving good communication from their haematology team at diagnosis facilitated less anxiety and greater understanding. Good communication was described as the HCP taking the time to explain the condition and providing written materials at diagnosis. 
medical professional you probably retain about a quarter of what they said. So I came way, and the only thing I remembered was Mono. And I thought, "What was that? What was the rest of that?" And I was trying to remember, cause that was it."

\section{FG1.5}

Patients described how GPs were important providers of information, where they had their blood tests and general healthcare but generally reported poor MGUS-specific knowledge. Patients reported they often felt more knowledgeable than their GP about MGUS. Patients who reported that their GPs were knowledgeable about MGUS appeared to better understand their diagnosis and felt reassured that they were receiving the best care possible. Patients were aware that GPs (and HCPs in general) have limited time available to inform themselves about all conditions, especially uncommon conditions like MGUS; but felt less anxious when their GP was knowledgeable. Patients wanted more GP-related resources to help GPs and patients, however, there was little indication as to what form these resources could take.

"So after the information, what I was told, it sinks in. and you do hear things like "you should be ok" [Laugh] Um, but when it sinks in, your first port of call, beyond the internet, is the GP. So I placed a call to the GP, and said to me "I don't know. I've never heard of this". FG1.5

"My doctor (GP) was on top of it the whole time like my doctor's been really good, and she has, she was she keeps me informed of everything that's happening and she explains everything she's my doctor. She's one of the only doctors that speaks my language if you know what I mean. I have all the confidence of the day in her cause she'll always go over the, the extra to help you." TI.1

Patients whose relatives/friends were qualified health care professionals (such as doctors, nurses and pharmacists) reported improved knowledge and understanding of their condition post-diagnosis. Patients whose partners were healthcare staff described how they prepared questions for their appointments.

"My wife (a nurse) had lists of questions, that she wanted me to ask. Now, and every time (Nurse Specialist) phones me now, I have those lists of questions now. FG1.6

\section{Experiences of MGUS related health services}

The final theme describes how patients were referred to MGUS health services and their experiences of health services and staff since diagnosis. Participants recalled different challenges and experiences, depending on the part of the patient pathway 
1 (pre-diagnosis, immediately post- diagnosis or a long-term MGUS patient) being

2 discussed.

4 Most patients described being diagnosed incidentally when being investigated for non-related medical issues, such as high blood pressure, co-morbidity appointments

6 (e.g. asthma), hospitalisation for acute illness (e.g. pneumonia) and acute injuries

7 (e.g. knee trauma). Typically, elevated paraprotein was initially investigated in the

8 haematology department, which interviewees said was located within the "cancer

9 centre", which generated fear and anxiety for some patients.

In one case, a patient previously under investigation for MM was relieved to have been diagnosed with MGUS; as they were not a "cancer patient"(FG1.1). Therefore, their experience of entering the MGUS health services was more positive than many of the other participants. Hospital's Cancer (entre). That very place. God bless everyone".

FG1.3

All patients were under surveillance via a telephone clinic and are informed of the results of their surveillance-mandated blood tests by the haematology clinical nurse specialists. This typically includes a discussion of the blood result scores, inquiries about the patient's general health and an opportunity for patient questions. Some patients kept a record of their blood results at each appointment. Patients were overwhelmingly satisfied with telephone surveillance, with none discussing negative experiences.

The telephone clinic offered an alternative to hospital-based consultant-led appointments by offering collaborative management between the haematology clinic and their primary care physician. The telephone clinic was reported to be more convenient and was especially beneficial for rural patients, for whom visiting the hospital and consultant in another town/city was seen as burdensome and timeconsuming. Patients also reported that telephone follow-up helped to reduce anxiety as they were able to avoid seeing cancer patients at the cancer centre (a reminder of what their diagnosis could progress to). Patients perceived the telephone clinic reduced burden on secondary care services (haematology staff especially doctors/consultants) and were supportive of improvements made to the service. 
"The telephone clinic I think to me that's probably really all I need it would seem, it would seem to me you know an awful waste of time to come down and taking up the doctor's time in the hospital or anything I mean this is only a... quick telephone conversation". TI.4

"Well, whenever I have the telephone appointment with the nurse I feel there's a little bit-... I'm wondering what I'm going to be told am I getting worse or is my health deteriorating. So I'd be glad whenever the conversation's finished." FG2.1

Despite an overall sense of satisfaction, most patients worried about the telephone clinic but realised that it was necessary. The waiting period between testing and results, which can be weeks, was highlighted as challenging. Patients reported anxiety during this waiting period and wondered if the blood tests would reveal an increase in disease markers and/or reveal progression to cancer (MM).

Patients encountered a range of communication styles from healthcare professionals when being diagnosed and when they sought MGUS information. The style of communication mediated their experience of the health service and overall satisfaction. Some patients reported excellent psychosocial care, with clinicians (specialists and primary care physicians) taking time to explain the MGUS diagnosis, which led to less diagnosis-related anxiety with patients reporting that they felt informed and supported. Haematology nursing staff were seen as having a positive communication style. Nurses provided reassurance, reduced anxiety and provided "peace of mind" through their psychosocial care, provision and explanation of information. Participants reported feeling more comfortable speaking with nurse specialists than doctors.

Other patients reported fewer positive interactions with doctors and recalled how these negative experiences were linked to feelings of isolation and uncertainty about their diagnosis, especially immediately post-diagnosis. Some patient's reported doctors in haematology not taking the time to describe their condition and being detached and dismissive of MGUS patients. While patients understood that other patients (especially cancer patients) required more care, they were disappointed at the lack of psychosocial care and empathy; with no/limited signposting to other information or being able to talk to someone about their diagnosis. This resulted in some patients having increased anxiety and feeling less informed. 
go". And the next patient in after you has got six months to live, or year. So they're focusing on him or her, rightly so.". FG1.5

Patients discussed a sense of isolation/uncertainty regarding their diagnosis, which many patients felt could be alleviated by providing support structures for meeting and interacting with other MGUS patients. MGUS patients are often not supported by cancer support charities or groups and can feel in "limbo" (FG1.1), both in cancer services and supportive structures such as the voluntary sector. Patients proposed developing two structures; in-person support groups (similar to cancer support groups) and volunteer peer support (local) contactable MGUS patients' postdiagnosis, for questions or concerns. Travel and low patient numbers were identified as threats to the long-term stability of in-person meet-ups. Focus group attendees (compared to telephone interviewees) were more positive about meetings/support groups. Some patients valued the availability of a contactable MGUS patient who they could speak to over a "coffee or glass of wine" FG2.1. Developing this indirect support may be useful addressing this unmet need.

"There's nothing (to help coping if individuals are struggling). you know, I just get through it, eventually. But it's not like I can lift the phone and ring (FG1.3). Lift the phone and ring (FG1.4), and say "How are you feeling today?" You know, "I'm feeling pretty (poor)". There's nothing out there, there's nobody out there. And that's because we're in limbo." FG1.1

\section{Discussion}

This novel study highlights the potentially negative impact that receiving and living with a MGUS diagnosis can have on patients, particularly at the point of diagnosis and time of follow-up appointments. Although receiving an MGUS diagnosis rarely had a life-changing impact, it did cause patients to re-evaluate their lives and to question their mortality. Most patients had a poor level of understanding of MGUS. Patients highlighted some issues in current MGUS service provision, especially in relation to information provision, but were positive about active surveillance provided by the nurse-led telephone clinic. Information was a powerful tool for patients, with good information and communication giving rise to improved understanding and reduced anxiety. The lack of available support for patients and their unwillingness to talk about MGUS to their families and friends, due to their own poor knowledge about MGUS and to avoid causing others anxiety was an issue for some patients. 
2 The emotional impact of MGUS was complex and nuanced to each individual. At the initial diagnosis, all patients reported experiencing shock at being diagnosed with an asymptomatic condition linked to cancer. This shock was similar to that reported for receiving positive results from population-level cancer screening (De Morgan et al., 2002; Prinjha et al., 2011), other premalignant conditions (Gough et al., 2003;

7 Hounsgaard et al., 2007; Kennedy et al., 2008; Shylasree et al., 2008) and

8 haematological malignancies (Swash et al., 2016). For many patients, this shock developed into anxiety and fear; the potential of developing cancer remained an active concern in the weeks and months following diagnosis. This is similar to the experiences of MM patients who reported having a sudden and shocking confrontation with their mortality, by a condition that they had never heard of (Hauksdóttir et al., 2017). This anxiety often regresses when chronic illness patients become accustomed to their diagnosis and the uncertainty is reduced (Mishel, 1999); similar to the experiences reported by the MGUS patients in this study. MGUS patients outlined the initial diagnosis period as having the highest psychosocial impact on their lives and an area where intervention could be implemented in the future. As most of the patients were several years' post-diagnosis, further research on newly diagnosed patients may provide greater insight into immediate impact of receiving a MGUS diagnosis.

Knowledge of MGUS was one of the strongest messages from the collective voice of the participants. Overall, patients had poor knowledge of MGUS at diagnosis. There was a clear distinction between the patients with MGUS knowledge and those with less knowledge. Those with more knowledge appeared to experience less anxiety and improved coping. In the wider MM literature, MM patients reported the initial gathering of information and developing knowledge as important to acquaint themselves with their condition and reduce their distress (Hauksdóttir et al., 2017).

Patients are often unable to absorb verbal information at diagnosis (Kessels, 2003). Anxiety and isolation can result if the information from HCPs is considered to be lacking, confusing, or inadequately explained (Prinjha et al., 2011). Many MGUS patients reported not receiving an information leaflet at diagnosis, one of the most frequent sources of healthcare information for patients (Kenny et al., 1998; Meredith et al., 1995). However, there may be a recall bias in not recounting receiving the information. However in our previous research, only $42 \%$ of haematologists provided information booklets at all diagnoses (McShane et al., 2017). Nevertheless, receiving 38 an information leaflet was linked to a more positive post-diagnosis experience. While acknowledging their condition may be lower priority for their doctor's time 
1 (compared to cancer patients), the need for more doctor-patient communication and

2 psychosocial care for MGUS patients was highlighted. Online searching was

3 described as difficult with patients reporting contradictory and confusing

4 information about MGUS. This finding is not surprising as haematological

5 malignancies have previously been reported as being among the least well

6 understood malignancies by patients (Department of Health, 2012).

8 The telephone clinic was universally preferred to the hospital clinic by patients for reducing anxiety related to visiting the "cancer place", and convenience (time and travel reasons). The telephone clinics, where the participants were recruited, follow the outreach model as proposed by Rawstron et al. (2007). Our study adds to the growing literature of positive patient-reported experiences with telephone clinics (Rawstron et al., 2007) and suggests that CNS-led clinics are a useful addition to MGUS service provision. The COVID-19 pandemic has increased telemedicine/remote monitoring, which may accelerate development of MGUS telephone clinics nationally and internationally. Some patients felt their wait time between phlebotomy and receiving results was too long and extended their anxiety. It would therefore be useful for service providers, to consider mechanisms to reduce the length of this waiting period.

MGUS patients were often reluctant to share details of their diagnosis with others outside their immediate family circle, due to low awareness and the feeling that other's issues were more important; especially if cancer related. This was felt by some participants as obstructing their ability to cope with the diagnosis. Compared to the support available for cancer patients, MGUS patients felt peer support and support groups were lacking. Similar to other premalignant conditions (De Morgan et al., 2002; Dowswell et al., 2012; Kennedy et al., 2008), MGUS patients agreed that there was benefit in meeting other patients to discuss shared experiences. Patients attending the focus groups reported positive experiences in being able to see and talk (often for the first time) to others with MGUS. An official website featuring life stories and blogs was also advocated by patients. This style is in keeping with mainstream health websites including 'NHS Choices' in the United Kingdom and charity websites who aim to supplement scientific facts with experiential information (Kelly et al., 2013).

35

\section{Clinical Implications}

A number of clear considerations came from the patients in this study. 
1. In line with the UK/Nordic guidelines (Bird et al., 2009), patient-friendly information and support is necessary at the point of diagnosis and thereafter for MGUS patients. Information booklets are available (e.g. Myeloma UK, Macmillan and the International Myeloma Foundation), however our results suggest these are not routinely provided at diagnosis. The information should be offered in various formats (verbal, paper and online) as patient needs differ. Information should advise on future follow-up procedures, disease progression and signs/symptoms to be aware of. Inclusion of 'life stories' of other MGUS patients in information leaflets was also suggested by patients who want to 'see' what other MGUS patients look like.

2. Many patients were diagnosed/followed-up initially in the local hematology department, however patients recalled this negatively as the 'cancer place' owing to cancer patients receiving their treatments in the same department. Improving the clinical environment may reduce patient anxiety, improve knowledge absorption and reduce future psychosocial distress.

3. The use of telephone clinics was positively endorsed by MGUS patients in this study. Telephone clinics reduce patient burden by reducing hospital visits, which can incur both financial and psychosocial costs (Overend et al., 2008; Rawstron et al., 2007); the feasibility of expanding this service should be explored

\section{Strengths and limitations}

Our study is based on the lived experiences of 14 MGUS patients in two health and social care trusts in Northern Ireland. Our sample size is comparable to other premalignant studies which have reported on small sample sizes (under 16) (Hounsgaard et al., 2007; Kennedy et al., 2008; Lee Mortensen and Adeler, 2010; Likes et al., 2008; Prinjha et al., 2006; Pruitt et al., 2008). Despite a small sample data, However, despite this, we feel as a research team that this was an accurate representation of the views of NI MGUS patients but that there were further insights that could found with more participants in some sub-themes, which may have not reached data saturation.

When considering the transferability of our findings to the wider MGUS population, the younger age of participants (present study 55.9 vs 74 years old; Li et al., 2016), and low risk MGUS profile should be considered. Due to the small numbers and similar age range (predominantly 50-70 years old), we were unable to explore the impact of age on experiences However, as patients diagnosed with MGUS at a younger age live longer with the knowledge of their condition and have an increased lifetime risk of developing MM; this younger group may receive a greater benefit from future interventions. 
1 Combining the focus group and interview data has potential drawbacks. The 2 increased interaction and sharing in the focus group led the data into different

3 avenues which were not as dynamic in the dyadic interviews. These diversions

4 provided greater insight of the lesser acknowledged and thought-of aspects of an

5 MGUS diagnosis. Correspondingly, the in-depth nature of interviews and individual

6 experiences provided finer details. Combining these modalities can cause

7 disconnects between the experiences of focus group and interview participants and

8 required the analysis to consider if the modality influenced this. However, we found

9 the codes and themes were consistent during the analysis of both modalities. The

10 use of the patient's CNSs as recruiters opens the possibility of recruitment bias,

11 however this is a common recruitment mechanism in premalignant conditions

12 (Kennedy et al., 2012; Pruitt et al., 2008). Information was not collected on those who

13 did not indicate interest in participating

\section{Conclusions}

16 Life-long surveillance provides patients with a periodical reminder of their MGUS diagnosis and its potential progression to cancer, which can cause anxiety. Measures such as provision of information leaflets to all patients at diagnosis, patient support groups, improved HCP communication and diagnosis/follow-up within a non-cancer clinical environment may help improve health and psychosocial wellbeing of MGUS patients.

\section{Conflicts of Interest and sources of Funding Statement}

The authors have declared no conflict of interest exists. The corresponding author had full access to all the data and final responsibility for the decision to submit for publication. Funding for this study was provided by a Cancer Translational Research Group Young Investigator Grant. At the time of the study, Dr Charlene McShane was in receipt of a Cancer Research UK Population Sciences Research Fellowship. 


\section{References}

Barbour, C.R., 2014. Doing Focus Groups. Sage Publications, Inc., London.

Bird, J., Behrens, J., Westin, J., Turesson, I., Drayson, M., Beetham, R., D'Sa, S., Soutar, R., Waage, A., Gulbrandsen, N., Gregersen, H., Low, E., 2009. UK Myeloma Forum (UKMF) and Nordic Myeloma Study Group (NMSG): guidelines for the investigation of newly detected $M$-proteins and the management of monoclonal gammopathy of undetermined significance (MGUS). Br. J. Haematol. 147, 22-42. https://doi.org/10.1111/j.1365-2141.2009.07807.x

Braun, V., Clarke, V., 2006. Using thematic analysis in psychology. Qual. Res. Psychol. 3, 77-101. https://doi.org/10.1191/1478088706qp063oa

De Morgan, S., Redman, S., White, K.J., Cakir, B., Boyages, J., 2002. "Well, have I got cancer or haven't I?" The psycho-social issues for women diagnosed with ductal carcinoma in situ. Heal. Expect. 5, 310-318. https://doi.org/10.1046/j.13696513.2002.00199.x

Department of Health, 2012. Cancer patient experience survey 2011/12. National report. London.

Dowswell, G., Ryan, A., Taylor, A., Daley, A., Freemantle, N., Brookes, M., Jones, J., Haslop, R., Grimmett, C., Cheng, K.-K., Sue, W., 2012. Designing an intervention to help people with colorectal adenomas reduce their intake of red and processed meat and increase their levels of physical activity: a qualitative study. BMC Cancer 12, 255. https://doi.org/10.1186/1471-2407-12-255

Gough, M.D., Gilliam, A.D., Stoddard, C.J., Ackroyd, R., 2003. Barrett's esophagus: patient information and the Internet. The patient's perspective. Dis. Esophagus 57-59.

Hauksdóttir, B., Klinke, M.E., Gunnarsdóttir, S., Björnsdóttir, K., 2017. Patients' Experiences With Multiple Myeloma: A Meta-Aggregation of Qualitative Studies. Oncol. Nurs. Forum 44, E64-E81. https://doi.org/10.1188/17.ONF.E64-E81

Hounsgaard, L., Petersen, L.K., Pedersen, B.D., 2007. Facing possible illness detected through screening-Experiences of healthy women with pathological cervical smears. Eur. J. Oncol. Nurs. 11, 417-423. https://doi.org/10.1016/j.ejon.2007.04.005

International Myeloma Working Group, 2003. Criteria for the classification of monoclonal gammopathies, multiple myeloma and related disorders. $\mathrm{Br}$. J. Haematol. 121, 749-57. https://doi.org/10.1046/j.1365-2141.2003.04355.x

Kelly, L., Jenkinson, C., Ziebland, S., 2013. Measuring the effects of online health information for patients: Item generation for an e-health impact questionnaire. Patient Educ. Couns. 93, 433-438. https://doi.org/10.1016/j.pec.2013.03.012

Kennedy, F., Harcourt, D., Rumsey, N., 2012. The shifting nature of women's experiences and perceptions of ductal carcinoma in situ. J Adv Nurs 68, 856-867. https://doi.org/10.1111/j.1365-2648.2011.05788.x 
Kennedy, F., Harcourt, D., Rumsey, N., 2008. The challenge of being diagnosed and treated for ductal carcinoma in situ (DCIS). Eur. J. Oncol. Nurs. 12, 103-11. https://doi.org/10.1016/j.ejon.2007.09.007

Kenny, T., Wilson, R.G., Purves, I.N., Clark, J., Newton, L.D., Newton, D.P., Moseley, D. V, 1998. A PIL for every ill? Patient information leaflets (PILs): a review of past, present and future use. Fam. Pract. https://doi.org/10.1093/FAMPRA/15.5.471

Kessels, R.P.C., 2003. Patients' memory for medical information. J. R. Soc. Med. 96, 219-22. https://doi.org/10.1258/jrsm.96.5.219

Kyle, R.A., Buadi, F., Vincent Rajkumar, S., 2011. Management of monoclonal gammopathy of undetermined significance (MGUS) and smoldering multiple myeloma (SMM). Oncology 25, 578-86. https://doi.org/167682 [pii]

Kyle, R.A., Durie, B.G.M., Rajkumar, S. V, Landgren, O., Blade, J., Merlini, G., Kröger, N., Einsele, H., Vesole, D.H., Dimopoulos, M., San Miguel, J., Avet-Loiseau, H., Hajek, R., Chen, W.M., Anderson, K.C., Ludwig, H., Sonneveld, P., Pavlovsky, S., Palumbo, A., Richardson, P.G., Barlogie, B., Greipp, P., Vescio, R., Turesson, I., Westin, J., Boccadoro, M., International Myeloma Working Group, Kyle, R.A., Durie, B.G.M., Rajkumar, S. V, Landgren, O., Blade, J., Merlini, G., Kröger, N., Einsele, H., Vesole, D.H., Dimopoulos, M., San Miguel, J., Avet-Loiseau, H., Hajek, R., Chen, W.M., Anderson, K.C., Ludwig, H., Sonneveld, P., Pavlovsky, S., Palumbo, A., Richardson, P.G., Barlogie, B., Greipp, P., Vescio, R., Turesson, I., Westin, J., Boccadoro, M., 2010. Monoclonal gammopathy of undetermined significance (MGUS) and smoldering (asymptomatic) multiple myeloma: IMWG consensus perspectives risk factors for. Leukemia 24, 1121-7. https://doi.org/10.1038/leu.2010.60

Kyle, R.A., Therneau, T.M., Rajkumar, S.V., Offord, J.R., Larson, D.R., Plevak, M.F., Melton, L.J., 2002. A long-term study of prognosis in monoclonal gammopathy of undetermined significance. N. Engl. J. Med. 346, 564-9. https://doi.org/10.1056/NEJMoa01133202

Kyle, R.A., Therneau, T.T.M., Rajkumar, S.V., Larson, D.R., Plevak, M.F., Offord, J.R., Dispenzieri, A., Katzmann, J. a, Melton, L.J., 2006. Prevalence of monoclonal gammopathy of undetermined significance. N. Engl. J. Med. 354, 1362-1369. https://doi.org/10.1002/ajh.22095

Lamb, M., Kane, E., Smith, A., Roman, E., 2019. Hospital activity before and after diagnosis of monoclonal gammopathy of undetermined significance (MGUS), in: Abstracts from the NCRI Cancer Conferences.

Landgren, O., Graubard, B.I., Kumar, S., Kyle, R.A., Katzmann, J.A., Murata, K., Costello, R., Dispenzieri, A., Caporaso, N., Mailankody, S., Korde, N., Hultcrantz, M., Therneau, T.M., Larson, D.R., Cerhan, J.R., Rajkumar, S. V., 2017. Prevalence of myeloma precursor state monoclonal gammopathy of undetermined significance in 12372 individuals 10-49 years old: a population-based study from the National Health and Nutrition Examination Survey. Blood Cancer J. 7, e618. https://doi.org/10.1038/bcj.2017.97

Landgren, O., Gridley, G., Turesson, I., Caporaso, N.E., Goldin, L.R., Baris, D., Fears, T.R., Hoover, R.N., Linet, M.S., 2006. Risk of monoclonal gammopathy of 
undetermined significance (MGUS) and subsequent multiple myeloma among African American and white veterans in the United States. Blood 107, 904-906. https://doi.org/10.1182/blood-2005-08-3449

Landgren, O., Katzmann, J., Hsing, A., 2007. Prevalence of monoclonal gammopathy of undetermined significance among men in Ghana. Mayo Clin. Proc. 82, 14681473.

Lee Mortensen, G., Adeler, A.L., 2010. Qualitative study of women's anxiety and information needs after a diagnosis of cervical dysplasia. J. Public Health (Bangkok). 18, 473-482. https://doi.org/10.1007/s10389-010-0330-1

Li, J., Smith, A., Crouch, S., Oliver, S., Roman, E., 2016. Estimating the prevalence of hematological malignancies and precursor conditions using data from Haematological Malignancy Research Network (HMRN). Cancer Causes Control 27, 1019-1026. https://doi.org/10.1007/s10552-016-0780-z

Likes, W.M., Russell, C., Tillmanns, T., 2008. Women's Experiences With Vulvar Intraepithelial Neoplasia. J. Obstet. Gynecol. Neonatal Nurs. 37, 640-646. https://doi.org/10.1111/j.1552-6909.2008.00291.x

Maatouk, I., He, S., Hummel, M., Hemmer, S., Hillengass, M., Goldschmidt, H., Hartmann, M., Herzog, W., Hillengass, J., 2019. Patients with precursor disease exhibit similar psychological distress and mental HRQOL as patients with active myeloma. Blood Cancer J. 9, 1-4. https://doi.org/10.1038/s41408-019-0172-1

McShane, C.M., Murphy, B., Lim, K.H., Anderson, L.A., 2017. Monoclonal gammopathy of undetermined significance (MGUS) as viewed by haematology healthcare professionals. Eur. J. Haematol. 1-7. https://doi.org/10.1111/ejh.12962

Meredith, P., Emberton, M., Wood, C., 1995. New directions in information for patients. BMJ 311, 4-5.

Mishel, M., 1999. Uncertainty in chronic illness. Annu. Rev. Nurs. Res. 17, 269-294.

Morse, J.M., Barrett, M., Mayan, M., Olson, K., Spiers, J., 2002. Verification Strategies for Establishing Reliability and Validity in Qualitative Research. Int. J. Qual. Methods 1, 13-22. https://doi.org/10.1177/160940690200100202

Nowell, L.S., Norris, J.M., White, D.E., Moules, N.J., 2017. Thematic Analysis : Striving to Meet the Trustworthiness Criteria 16, 1-13. https://doi.org/10.1177/1609406917733847

Overend, A., Khoo, K., Delorme, M., Krause, V., Avanessian, A., Saltman, D., 2008. Evaluation of a nurse-led telephone follow-up clinic for patients with indolent and chronic hematological malignancies: A pilot study. Can. Oncol. Nurs. J. 18, 64-68. https://doi.org/10.5737/1181912x1826468

Prinjha, S., Evans, J., McPherson, A., 2006. Women's information needs about ductal carcinoma in situ before mammographic screening and after diagnosis: a qualitative study. J. Med. Screen. 2006 13, 110-114.

Prinjha, S., Evans, J., Ziebland, S., McPherson, a, 2011. "A mastectomy for something that wasn't even truly invasive cancer". Women's understandings of having a 
mastectomy for screen-detected DCIS: a qualitative study. J. Med. Screen. 18, 34-40. https://doi.org/10.1258/jms.2011.010143

Pruitt, S.L., Parker, P.A., Follen, M., Basen-Engquist, K., 2008. Communicating colposcopy results: what do patients and providers discuss? J. Low. Genit. Tract Dis. 12, 95-102. https://doi.org/10.1097/LGT.0b013e31815a5142

QSR International Pty Ltd, 2015. NVivo qualitative data analysis Software.

Rawstron, A.C., Jones, R.A., Ferguson, C., Hughes, G., Selby, P., Reid, C., Dalal, S., Howard, M., Smith, G., Hillmen, P., Owen, R.G., Jack, A.S., 2007. Outreach monitoring service for patients with indolent $B$-cell and plasma cell disorders: a UK experience. Br. J. Haematol. 139, 845-848. https://doi.org/10.1111/j.13652141.2007.06864.x

Shylasree, T.S., Karanjgaokar, V., Tristram, A., Wilkes, A.R., MacLean, A.B., Fiander, A.N., 2008. Contribution of demographic, psychological and disease-related factors to quality of life in women with high-grade vulval intraepithelial neoplasia. Gynecol. Oncol. 110, 185-189. https://doi.org/10.1016/j.ygyno.2008.04.023

Smith, D.P., Supramaniam, R., King, M.T., Ward, J., Berry, M., Armstrong, B.K., 2007. Age, health, and education determine supportive care needs of men younger than 70 years with prostate cancer. J. Clin. Oncol. 25, 2560-2566. https://doi.org/10.1200/JCO.2006.09.8046

Stokes, D., Bergin, R., 2006. Methodology or "methodolatry"? An evalution of focus and depth interviews. Qual. Mark. Res. An Int. J. Artic. 9, 26-37. https://doi.org/10.1108/13522750610640530

Swash, B., Hulbert-Williams, N., Bramwell, R., 2016. 'Haematological cancers, they're a funny bunch: A qualitative study of non-Hodgkins lymphoma patient experiences of unmet supportive care needs. J. Health Psychol. July, 1-12. https://doi.org/10.1177/1359105316660179

Therneau, T.M., Kyle, R.A., Melton, L.J., Larson, D.R., Benson, J.T., Colby, C.L., Dispenzieri, A., Kumar, S., Katzmann, J.A., Cerhan, J.R., Rajkumar, S.V., 2012. Incidence of monoclonal gammopathy of undetermined significance and estimation of duration before first clinical recognition. Mayo Clin. Proc. 87, 1071-9. https://doi.org/10.1016/j.mayocp.2012.06.014

Wadhera, R.K., Rajkumar, S.V., 2010. Prevalence of monoclonal gammopathy of undetermined significance: a systematic review. Mayo Clin. Proc. 85, 933-42. https://doi.org/10.4065/mcp.2010.0337 
Table 1 Demographic characteristics of the patients

CHARACTERISTICS

(\%/RANGE)

\begin{tabular}{|c|c|c|}
\hline \multicolumn{2}{|l|}{ GENDER } & \multirow[b]{2}{*}{$8(57)$} \\
\hline & Male & \\
\hline & Female & $6(43)$ \\
\hline \multicolumn{3}{|l|}{ AGE } \\
\hline & $41-50$ & $2(14.3)$ \\
\hline & $51-60$ & $5(35.7)$ \\
\hline & $61-70$ & $6(42.8)$ \\
\hline & $71-80$ & $1(7.2)$ \\
\hline \multicolumn{3}{|c|}{ MARITAL STATUS } \\
\hline & Married & $13(92.8)$ \\
\hline & Divorced & $1(7.2)$ \\
\hline \multicolumn{3}{|c|}{ LEVEL OF EDUCATION } \\
\hline & Finished Secondary School ('O' Levels) & $3(21.4)$ \\
\hline & Finished Secondary School ('A' Levels) & $3(21.4)$ \\
\hline & $\begin{array}{l}\text { Further Education (attended a Technical } \\
\text { College) }\end{array}$ & $3(21.4)$ \\
\hline & Undergraduate/Master’s degree & $5(35.8)$ \\
\hline \multicolumn{2}{|c|}{ AGE AT DIAGNOSIS } & \\
\hline & Mean age in years & $55.9(45-74)$ \\
\hline TELEPHO & REVIEW & \\
\hline
\end{tabular}


Follow-up time in months

$5.6(3-12)$

PLACE OF RESIDENCE

Urban

$9(54)$

Rural

OTHER LONG-TERM CONDITIONS

Yes

No

8 (57)

3 Table 2 Sociodemographic factors of individual patients

\begin{tabular}{|l|l|l|l|}
\hline Study ID & Sex & Age Range & Education \\
\hline FG1.1 & Male & $41-50$ & $\begin{array}{l}\text { Undergraduate/Master's } \\
\text { degree }\end{array}$ \\
\hline FG1.2 & Male & $61-70$ & Further Education \\
\hline FG1.3 & Male & $51-60$ & Further Education \\
\hline FG1.4 & Female & $51-60$ & $\begin{array}{l}\text { Undergraduate/Master's } \\
\text { degree }\end{array}$ \\
\hline FG1.5 & Male & $41-50$ & $\begin{array}{l}\text { Undergraduate/Master's } \\
\text { degree }\end{array}$ \\
\hline FG1.6 & Female & $61-70$ & 'A' Levels \\
\hline FG2.1 & & & $\begin{array}{l}\text { Undergraduate/Master's } \\
\text { degree }\end{array}$ \\
\hline FG2.2 & Male & $61-70$ & 'A' Levels \\
\hline TI.1 & Male & $51-60$ & 'A' Levels \\
\hline TI.2 & Male & $51-60$ & 'O' Levels \\
\hline TI.3 & Female & $51-60$ & Further Education \\
\hline TI.4 & Female & $61-70$ & $\begin{array}{l}\text { Undergraduate/Master's } \\
\text { degree }\end{array}$ \\
\hline TI.5 & & $61-70$ & 'O' Levels \\
\hline TI.6 & Male & $71-80$ & 'O' Levels \\
\hline & Female & $61-70$ & \\
\hline
\end{tabular}


The Psychosocial impact of an MGUS diagnosis

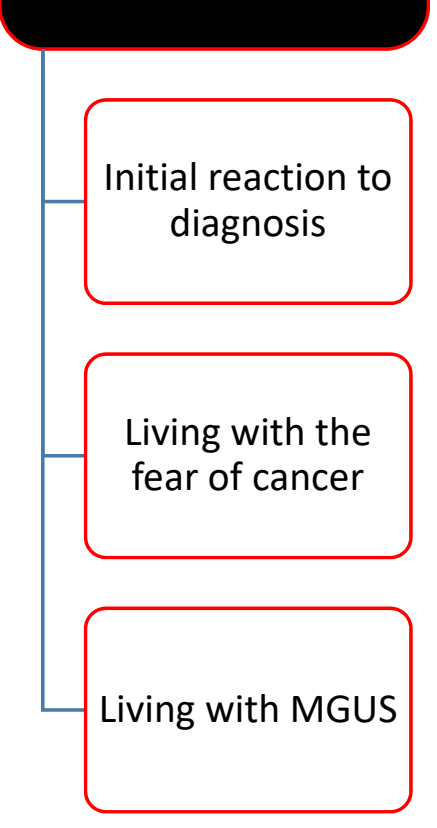

3 Figure 1. Coding tree for themes and subthemes. 
2

3 Blain Murphy: Formal analysis, Writing - Original Draft, Writing- Reviewing and $4 \quad$ Editing

5 Charlene M. McShane: Conceptualization, Investigation, Writing- Reviewing and 6 Editing, Funding Acquisition

7 Olinda Santin: Supervision, Investigation, Writing- Reviewing and Editing, Funding

8 Charlene Treanor: Investigation, Writing- Reviewing and Editing, Funding

9 Bronagh Bryne: Conceptualization, Investigation, Writing- Reviewing and Editing,

10 Funding

11 Michael Donnelly: Supervision, Writing- Reviewing and Editing

12 Lesley A. Anderson: Conceptualization, Supervision, Writing- Reviewing and Editing,

13 Funding Acquisition 